\title{
Enquête
}

Archives de la revue Enquête

5 | 1989

Biographie et cycle de vie

\section{Life story beyond illusion and events past}

\section{Wolfram Fischer-Rosenthal}

\section{(2) OpenEdition}

\section{Journals}

Electronic version

URL: http://journals.openedition.org/enquete/110

DOI: 10.4000/enquete. 110

ISSN: 1953-809X

\section{Publisher.}

Cercom, Éditions Parenthèses

Printed version

Date of publication: 2 March 1989

\section{Electronic reference}

Wolfram Fischer-Rosenthal, « Life story beyond illusion and events past », Enquête [Online], 5 | 1989,

Online since 27 June 2013, connection on 30 April 2019. URL : http://journals.openedition.org/ enquete/110 ; DOI : 10.4000/enquete.110

This text was automatically generated on 30 April 2019. 


\title{
Life story beyond illusion and events
} past

\author{
Wolfram Fischer-Rosenthal
}

1 My thesis today in this paper is that a narrated life story, i. e. an oral presentation of one's own life is more than the fiction of a narcistic storyteller and also more than a life-record of events past in which is simply piled up or sedimented what happened chronologically. The latter conception seems to me as the rigid counterpiece to the former, the "desillusionistic" overreaction to the "illusion"-reproach, which is widespread in sociological circles and unifies arch-positivists and neo-marxistics, neo-structuralistics, post-existentialistics and what-not-istics who don't like each other otherwise.

2 Before I start to develop my argument, I give you the base line: I think ordinary people need a life story of their own in order to get through -through what?- through everything, the ordinary and the extraordinary, through life in the sense of everything that can happen and has happened. While I encounter the world that has been built before I entered this stage, I have to know a few simple questions:

- what is going on?

- what is happening to me?

- what am I doing and am I to do?

- what is my part in things happening?

- what do others think of me?

And I could sum up all that in one question:

- who am I myself?

3 I maintain that the Greek philosopher's famous imperative "gnothi seauton!", "know yourself!", is executed on everyday level -in small change- in thematizing yourself in autobiographical narratives. To be even more to the point: if you are not able to give your story, you will have extreme difficulties to orient yourselves in all kinds of interactional situations and you are likely to decompose in social and bodily terms, you will not survive in any sense of the word. 

story fulfill such an important task. I shall try to give a few hints, using the fiction -and events- past concepts of life story as two focusses of an eliptical figure making a whole. I shall start my argument introducing two simple events and follow them through possible biographical textualization. In doing so I shall prove the deficiency of the linear and fictional conception and develop a fuller notion of life story beyond illusion and events past.

"Biography is made of events past" is the simple proposition we'll start with. A succession of events that come into being and disappear line up like perls on a string, chronologically ordered and directed from now to then or then to now.

Lets take two pasts events to prove the concept.

1. A swimming guard at the North Sea watches a man and two little boys walking back on the beach from swimming being cut off by strong and deep flooding waters. The guard first pulls one kid into save waters, and then gives relief to the almost exhausted and for help shouting man in taking over the second kid into safety. Nobody is injured. The event lasted about twenty minutes and took place in 1983; it was not fixed in any records nor made public.

2. The medical faculty of a German university decided to install a second chair for a sociologist. The position was filled two years later in 1986. The event and name of the appointed scholar was published in the university's newspaper and elsewhere.

7 If we first try to define the "traces in reality" of both events and refrain from any experiencial category's the first event has so to say no result because the objective reality has not been changed by the event, the objective world was the same before and after the event. The second event has brought a new teacher into a faculty, so the event has set up the count of teachers one point. Anyway, whatever effects, as pure events that happened at a point in time are they past and over.

8 Now, it is trite to say that in the context of my argument a sequence of events cannot only be stated in terms of the calendar but in relation to somebody who was involved in the events. So let's assume the man with the two boys in danger is the very same who was appointed by the faculty as sociologist. He himself is the link of otherwise separate events, they are part of his biography, according to the first concept just piled up one after the other "in his life" -or could we say inscribed in his "life-records"?

9 For this sociologist both events are today -granted that he is still around- events past, sedimented elements of his biography. In which sense are they past is the crucial question. Are they past whithout a trace? Then they cannot be present as an element of this man's biography, since this is obviously something actual. On the other hand, if the events have a still actual result, in which sense can they be past? Event two seems easier, more "objective": one may say that this person has taken a certain occupational position and he once became what he still is. This presence is an objective biographical gain ranging some time back, it is not past, though the instalment itself is a past event. Speculating we can put up hypotheses what is happening to a person who faces such occupational transitions (supposed we know about that special social field).

10 If we ask further, if there is any access to the events past by this man, we can assume that they are "in his memory", that they can be retrieved in one way or another. Consequently, since the memory is an inaccessible treasure for all others but the one who holds it, the put in store events can be shared by thirds only via talking about it. 
11 Both amounts to saying, we -who were not part of the events- do not know what really is going on, as long as the bearer of this position does not give us word, what the event "meant" and "means" for him, in which sense it is past or actual for him.

This sounds like a difficult almost metaphysical problem, but we all are more or less experts in that, we tell stories of "what we experienced", we give descriptions when we do not want to convey personal involvement, and we start arguments, when we try to persuade others and talk them into some practical action.

13 If the second event is thematized biographically in the story of the one who experienced it, we may not only hear, how things developped, but as well that this event was a long expected and prepared for step in his occupational strand, his installment a happy day which still shines on today's routine business and nourishes expectations of further success. Or we may hear that he curses this very day because none at the consecutive expectations did become real and he feels that "what he really wanted" is farther away than ever. Listening to him, we may have second thoughts, but we have to have his first ones.

Looking at sea-side event things are worse. Though once happened "in space and time", in the outer reality, we do not know, what kind of traces, effect the almost bathing accident had on this man. Again, he has to tell us what this meant for him and still means. What effects he may see and what it is that he remembers as of today. We may hear that he almost forgot the event, but that it was a happy day, his little mistake did not harm anybody, thanks to the help he had. Or we may hear that he is glad about what happened, but sometimes is still fantasizing what could have happened in the worst case, an agonizing and a perspiring image that steals his sleep at certain times up till now. We may also hear that it was a shocking experience, a narrow escape from death and from a family tragedy. Fellings of still present guilt and since then a permanent loss of enjoying to swim and fits of anxiety when moving in open waters may be articulated. There is a "trace of the crime" in his body or bodily and actional capacity, so to speak. Again, the one who is listening may have his second thoughts, but the first-person account is needed for indepth third-person reconstructions.

In both events past is not simply past, memory is not a machine-like data base or an materialized inscription, but a flexible source in terms of an actual interpretation. This is necessary in order to put the event in the right biographical "place", which is more than just a calendar date. The model of linear upstacking "pure events" as substance of biography is deficient. There is not "event" in the biographical sense outside of experience.

All that amounts to saying that we need to know by the one who links together the events in "having lived through" them by means of articulating his experience. This thematization is always done "now", it is present and the actually valid perspective onto things past provides with the interpretational twist of "what it all means". I call that perspective the "present perspective", it is constitutive for any biographical account. It is operating as well in a short story of a single event in everyday discourse between family members as in a biographical interview lasting for hours in a sociological research context.

There is not event of biographical relevance unless it is thematized and interpreted from a present perspective. 

and affords interpretation, more comes into focus. We realize that events that did not happen in the past and expected future events are part of the biographical horizon framing the practical possibilities and experiencial orientations. Put dramatically, not only the life we lived is part of biographical accounts and self-presentation but as well the life we did not live and we wait for.

If the first event of our exemple is experienced traumatic with even bodily consequences, a reduced ability to swim and anxiety, then this depends on what did not happen, namely the tragic family accident. What further follows is a future orientation of how to behave in unknown seas with tides. The second event can be reinterpreted in terms of how things were today, if the appointment would not have been assigned, and/or what to do next in occupational planning considering all experiences going along with that event and professional stage.

The evident orientational character of "real possibilities" (missed events, disappointed expectations) and actual expectations (future orientation) is an important principle of constituting one's own life story. extent undefined and has to be defined by "experience, validating living through. In everyday life we need a biographical construction in the sense that we need to understand what we face, to comprehend others and ourselves. This understanding always is a selection out of several possible choices -granted the impossible ones. I would not call it illusion, not even fiction, but it is an interpretation symbolically constructed out of socially validated patterns and emerging experiences that have not been the case before. The material basis of this is language and its actual use in discourse between copresent interactants. We live on these constructions, and I don't mind, if they are called illusions, as long as I don't have better ones to orient myself. There may be inconsistencies in my constructions and open ends -but I don't refer to that- unless I need it.

This is the aspect of the ordinary, practically oriented self. The selecting biographical frame is a construction which is needed, but it is not a closed system at the simple command of the bearer. It is reality-open, flexible to constitute new experience and horizons. This is in sharp contrast to Bourdieu's notion of biography fulfilling the claim of Staatsräson ("raison d'État"). 
Retrievable memories are not to be interpreted only in one direction, though I practically do so. This implies an abundance of opened ends and further interpretations even in a short oral account under thematically rather focussed conditions and under the operating of very distinct intentions. The narrator himself can reorganize his stories, i.e. nothing else than constituting his experiences under the condition of emerging events.

This is one level of biographical construction the illusion-reproach does not realize or totally misses.

The other problem of the illusion-critique arises from having a short-cut version of the biography-research at hand, a dummy on which to shoot is good for practice but does not hit the real goal. In other words, the possibilities of a deep structural analysis of oral biographical accounts are not known or not taken into consideration.

The tacit presupposition of the critique is, that the analytical work suffices in reproducing the face values and explicit intentions of the biographer, thus missing any kind of structural conditions. This presupposition is missing a great part of biographical research which is congruent with Bourdieu's explicit aim to have analysed implicit operating dimensions of biography constitution underneath representations of subjective intentions.

31 Biographical research does know about the problem of the difference between talking about action and action itself, does know about the possible different versions of a biographical account, i.e. about the perspectivity of its data. This perspectivity is just the point of departure, not the safe port of destination. Even biography researcher do have "second thoughts" or -put more decently- have developed methods and tools to reconstruct general deep structural elements through case work.

2 What are the tools or how can general patterns of biographical construction be gained from stories? This -of course- is a new paper, at least, so I have to irresponsibly short.

The hermeneutic approach takes the text seriously as constituting experience in discoursal setting and tries to find out, "what really drives this text/meaning production". This cannot be found in categorial coding, labeling and other types of a logic of subsumtion but in tedious efforts to find out, what this text is about and what has generated the meaning (which is always a possible meaning) of the text.

34 The basic "technical" procedure is to reconstruct the selections of the biographical text as sequentially opening up thematic fields and making consecutive choices. The ex-post construction of the narrator in sequential manner during linear "flow" of narration time is utilized to build up a waste horizon of possible development, choices, experiences which gives the background to understand the actual choices. The interactional parts of the researcher/interviewer have to be taken into account as selecting agent as well, of course.

35 Since the text does not only refer back to the narrator but as well to his world, reconstruction work of objectively accessible elements of this world is the second important level of analysis. Ordered according to the chronological level of the objective circumstances are analyzed as structural conditions for the selections. Here is the slot, where other types of non-hermeneutical sociological knowledge has to be taken into account (or may be generated).

Both levels of analytical work allow finally generalizations on the deep structure of the case beyond the explicit intentions of the narrator and beyond the case itself. 